\title{
RETRATO DAS POLÍTICAS PÚBLICAS GOVERNAMENTAIS BRASILEIRA PARA A JUVENTUDE NOS ANOS 2000
}

\author{
RAFAEL GARCIA BARREIRO* \\ ANA PAULA SERRATA MALFITANO ${ }^{* *}$
}

\begin{abstract}
RESUMO
Na última década, o investimento público brasileiro para a juventude constituiu um discurso sobre política pública no cenário nacional. Destaca-se a criação da Secretaria Nacional de Juventude, em 2005. Com o intuito de mapear o que vem ocorrendo, traçou-se um panorama histórico das ações políticas nos últimos 12 anos, no nível federal, com base nos documentos oficiais e nas leis disponibilizadas. Segundo os registros oficiais, conclui-se que houve um avanço na agenda pública para esta população, sendo que há um enfoque predominante em um recorte de classe social, priorizando políticas para a juventude pobre.
\end{abstract}

PALAVRAS CHAVE: POLÍTICA PARA A JUVENTUDE, DIREITOS SOCIAIS, BRASIL

* $\quad$ Mestre pelo Programa de Pós-graduação em Terapia Ocupacional da Universidade Federal de São Carlos, São Carlos, SP, Brasil. Professor Assistente do curso de Terapia Ocupacional da Universidade de Brasília. E-Mail: rgbarreiro@gmail.com.

** Pós-Doutora pela University of Western Ontario, Canadá. Doutora em Saúde Pública. Pesquisadora do Laboratório METUIA. Professora Adjunta do Departamento de Terapia Ocupacional e do Programa de Pósgraduação em Terapia Ocupacional da UFSCar.

E-Mail: anamalfitano@ufscar.br. 


\title{
RETRATO DE LAS POLÍTICAS PÚBLICAS GUBERNAMENTALES BRASILEÑAS PARA LA JUVENTUD EN LOS AÑOS 2000
}

\begin{abstract}
RESUMEN
En la última década, la inversión pública brasileña para la juventud ha producido un discurso de las políticas públicas en el ámbito nacional, destacando la creación de la Secretaría Nacional de la Juventud en 2005. Esto con el objetivo de consignar lo que está ocurriendo y elaborar una visión histórica de las acciones políticas en los últimos 12 años a nivel federal basado en documentos y leyes oficiales disponibles. De acuerdo con los registros oficiales, es posible concluir que no ha habido un gran avance en la agenda pública para esta población, aun habiendo un interés predominante en la clase social, con la priorización de políticas para la juventud pobre.
\end{abstract}

\author{
PALABRAS ClAVE: POLÍTICA PARA LA JUVENTUD, \\ DERECHOS SOCIALES, BRASIL
}

\section{PORTRAIT OF BRAZILIAN GOVERNMENT PUBLIC POLICY FOR YOUTH IN 2000}

\begin{abstract}
In the last decade, the Brazilian public investment for youth has produced a speech about public policy at the national level. It is important to mention the creation of the National Youth Secretariat in 2005. In order to map what is happening, it was developed a historical vision of political actions in the last 12 years at the federal level, based on official documents and official laws available. According to official records, it is concluded that there has not been a progress on the public agenda for this population, despite having a predominant focus in social class, prioritizing social policies for poor youth.
\end{abstract}

KEY WORDS: YOUTH POLICY, SOCIAL RIGHTS, BRAZIL 


\section{INTRODUÇÃO}

A entrada na agenda política das questões para a juventude como objeto de intervenção do poder público traz desdobramentos nas ações estabelecidas em diferentes esferas políticas (educação, economia, assistência social, entre outros). Para que isso ocorra é necessário que haja o reconhecimento da demanda (ou do problema) e a possibilidade de intervenção pública sobre ele (Sposito, 2007).

As ações políticas desenvolvidas no Brasil na última década, conforme declarado em documentos oficiais, originam-se da perspectiva do jovem como um sujeito de direitos. A criação de uma agenda específica e formatada para a juventude é recente e seu processo de conquista tem sido complexo, havendo um movimento global na busca da defesa e da efetivação dos direitos da população jovem (Silva e Lopes, 2009).

Não é por acaso que existe atualmente um movimento político para a juventude, pois, pelas características demográficas, os países latinoamericanos e caribenhos vivem uma «onda jovem»(Barbiani, 2007), formada por uma população majoritariamente juvenil. Compõe um setor que, por um lado, carece de estruturas dentro das políticas públicas e, por outro, é um nicho de mercado promissor e em potencial.

Frente a estas características, o Brasil possui uma população jovem formada por 34.236.060 habitantes (IBGE, 2013), o que significa $18 \%$ da população do país com idade entre 14 e 24 anos. Comparado aos demais países da América Latina, este número torna-se relevante, referindo-se a aproximadamente $32 \%$ dessa população na América Latina e Caribe que, segundo dados da Organização Mundial do Trabalho, somam cerca de 106 milhões de jovens (OIT, 2013). Portanto, o Brasil tem uma parcela significativa da população jovem latinoamericana, justificando a importância de entender a sua construção de políticas para a juventude.

Por sua representatividade populacional, os jovens vão conquistando e assumindo a condição de sujeitos com uma especificidade, remetendo à ação e à experiência da juventude em cenários, práticas, mercados e políticas (Barbiani, 2007). Trata-se da entrada na esfera pública desse grupo social, trazendo para a arena suas demandas e particularidades. Compreende-se aqui a noção de espaço público com base em Hanna Arendt, ou seja, como um espaço utilizado para o debate na relação entre a sociedade civil e o Estado (Arendt, 2007).

Tendo por base a relevância da temática da juventude em geral, e da juventude brasileira em particular, o presente artigo apresenta o 
atual panorama das ações políticas para a juventude no âmbito federal brasileiro. Para tanto, foram consultados documentos e cartilhas disponibilizados nos sítios eletrônicos dos órgãos públicos federais, dentre eles: a Secretaria Nacional da Juventude, a Secretaria Geral da Presidência da República (SGPR) e o Ministério de Desenvolvimento Social e Combate à Fome (MDS). Realizou-se também uma consulta nos decretos de lei e emendas constitucionais relacionados à juventude, por meio do acesso aos sítios eletrônicos da Câmara dos Deputados e do Senado Federal do Brasil. Ainda foram consultados documentos oficiais disponibilizados em meio impresso pela Secretaria Nacional da Juventude através do contato presencial realizado com o gestor público. Estabeleceu-se um recorte nos últimos 12 anos acerca das ações políticas propostas para a juventude, tomando como base a institucionalização e a consolidação delas no cenário nacional.

Cabe ressaltar que as proposições, informações e reflexões aqui expostas baseiam-se nos documentos oficiais analisados, ou seja, no discurso político da gestão que redigiu o material. Embora se considere de grande relevância o conhecimento das diretrizes teóricas priorizadas pelos governos, destaca-se que as análises contêm limites por serem baseadas "apenas" em documentos. Portanto, a partir da perspectiva dos governos, frente às ações instauradas. Aponta-se como necessária e relevante a averiguação no cotidiano dos serviços sobre o que vem, efetivamente, ocorrendo, para além das proposições formalmente escritas, sugerindo a elaboração de investigações nessa perspectiva.

\section{APONTAMENTOS SOBRE O HISTÓRICO DAS AÇÕES POLÍTICAS PARA A JUVENTUDE NO BRASIL}

O Brasil, assim como muitos países da América Latina, viveu anos de ditadura militar, entre as décadas de 1960 e 1980, período no qual as dimensões sobre direitos sociais não eram priorizadas (Gaspari, 2002). Assim, seguindo a lógica das políticas sociais em geral, não havia um enfoque sobre a juventude, embora já houvesse um movimento mundial para traçar diretrizes com a abordagem nesse grupo populacional. Em 1965 o Brasil assinou a «Declaração sobre o Fomento entre a Juventude dos Ideais de Paz, Respeito Mútuo e Compreensão entre os Povos», elaborado pela Organização das Nações Unidas (Silva e Andrade, 2009). Apesar de ter sido importante pela abordagem ao jovem pelas características de sua fase da vida, e não sob o enfoque de suas 
«problemáticas», a participação do Brasil não criou nenhum impacto no cenário nacional.

Vinte anos depois, em 1985, a ONU promulgou o Ano Internacional da Juventude, juntamente ao contexto histórico do fim da guerra fria. Tornou-se relevante a discussão acerca da nova divisão internacional do trabalho, com o aprofundamento da globalização dos mercados, de «desterritorialização» dos processos produtivos e de flexibilização das relações de trabalho (Novaes, 2012), que influenciaram fortemente os jovens e sua possibilidade de inserção e autonomia social. Nesse contexto, visualizando sobre os anos de crise econômica vivenciados nos anos 1980, as questões acerca da juventude e trabalho tiveram repercussões na esfera nacional.

Com a reinauguração da democracia no Brasil, em meados da década de 1980, houve a possibilidade de institucionalidades estatais na direção da elaboração e implementação de políticas públicas, em diversas questões sociais.

No que se refere ao público infanto-juvenil, privilegiou-se, inicialmente, a infância, traçou-se alguns apontamentos para a adolescência, porém não houve nenhum aprofundamento no dispositivo de lei para a juventude (Malfitano, 2011). Portanto, o termo «juventude» não correspondia às ações naquele momento estabelecidas.

Exemplo disso foi a promulgação do Estatuto da Criança e do Adolescente (Brasil, 1990), impulsionada e debatida por movimentos sociais, constituindo princípios para a garantia de direitos das crianças e dos adolescentes e deveres do Estado frente a aquela população. $\mathrm{O}$ Estatuto é um marco jurídico, pois, além de ser a primeira legislação latino-americana característica para a infância e a adolescência reconhecendo seu lugar de direito e de prioridade na sociedade (Malfitano, 2011), impulsionou a discussão sobre outros grupos populacionais, como a juventude, trazendo-os para a esfera pública.

$\mathrm{Na}$ continuidade desse processo, as ações políticas voltadas ao público juvenil começaram a ter maior visibilidade a partir da eleição de Fernando Henrique Cardoso para presidente, em 1994, sobretudo com ações baseadas na ideia de prevenção à violência e de controle dos comportamentos daquele grupo populacional. Em outras palavras, ações de efeito compensatório aos problemas socioeconômicos que atingiam a juventude (Sposito e Carrano, 2003) começaram a ser implementadas. Eram propostas com base em uma concepção simplista de violência, focando apenas no ato em si e não em suas múltiplas causas e relações com uma estrutura de desigualdade, por exemplo, o 
que possibilita inferir que havia um recorte sobre a juventude pobre, a partir de um discurso conservador e de sua culpabilização, sob uma organização do Estado para a realização do controle social (Hein e Cárdenas, 2009).

Em paralelo ao movimento governamental, que não chegou a estruturar uma política específica, mas somente ações e projetos isolados, surgiram organizações e grupos juvenis com representação em vários campos (entre eles cultural, esportivo, ambiental, estudantil, políticopartidário, movimentos étnicos e em prol da igualdade de gênero, associações de bairro e outros) que pressionavam o poder público a reconhecer os problemas específicos que os afetavam e a formular políticas que contemplassem ações para além daquelas que apenas viam os jovens como sinônimos de problema (Abramo, 2005). Tais demandas emergiam da compreensão dos jovens como sujeitos de direitos, definidos não por suas incompletudes ou desvios, mas por suas especificidades e necessidades, que deveriam ser reconhecidas no espaço público como demandas cidadãs legítimas (Silva e Andrade, 2009).

Sposito (2007) assinala a visibilidade que decorreu da expressiva ação da Organização das Nações Unidas para a Educação, a Ciência e a Cultura (UNESCO), e de outros atores desde 1997, realizando uma série de parcerias com o governo federal. Essas ações alcançaram rapidamente os meios de comunicação, ampliaram as repercussões dos diagnósticos realizados sobre a condição juvenil e abriram canais de legitimidade para a criação de projetos de intervenção. Ainda, criaram a pauta da agenda política em torno dos jovens nos diferentes níveis de governo.

Os debates foram sendo intensificados na década de 2000. Tal fato pode ser averiguado nas eleições presidenciais de 2002, quando diversos movimentos de juventude, convocados pela Organização Brasileira de Juventude (OBJ), UNESCO e a Ordem dos Advogados do Brasil (OAB), reuniram-se para redigir uma carta de reivindicações denominada «Agenda jovem 2002», tendo como base as experiências das organizações e os consensos internacionais (Brasil, 2011). A carta elaborada serviu como dispositivo para os três principais candidatos à presidência da república, na ocasião, apresentarem propostas específicas para a juventude em seus planos de governo.

Na sequência, foi eleito para presidência Luiz Inácio Lula da Silva (2002-2005), primeiro momento em que se articulou uma agenda política para a juventude, nomeada especificamente para esse público. 


\section{A ENTRADA NA AGENDA GOVERNAMENTAL DE UMA POLÍTICA PÚBLICA ESPECÍFICA PARA A JUVENTUDE NO BRASIL: ANOS 2000}

O movimento de discussão de uma agenda para a juventude iniciouse, por solicitação da Presidência da República, com a criação da Comissão Especial de Políticas para a Juventude (Cejuvente), em 2003, sediada na Câmara Federal de Deputados. Os princípios naquele momento debatidos tiveram papel significativo na constituição do panorama atualmente estabelecido. No ano de 2004, em caráter experimental, foram realizadas Audiências Públicas e Conferências Estaduais de Juventude resultando, naquele mesmo ano, na Primeira Conferência de Juventude, realizada pela Câmara dos Deputados (Brasil, 2010).

Aquele encontro ofertou subsídios para a criação do Projeto de Emenda Constitucional (PEC) N³94/2005, que propôs alterações em textos da Constituição Federal Brasileira (Brasil, 1988). O Capítulo VII do Título VIII teve a inclusão do termo «do jovem», passando a se denominar «Da Família, da Criança, do Adolescente, do Jovem e do Idoso»; dando visibilidade também a esse grupo etário. O artigo 227 que, originalmente, enfocava as crianças e os adolescentes, foi acrescido dos jovens, com o intuito de incluir os interesses relacionados à juventude. Essa proposta foi aprovada e promulgada em 2010 como Emenda Constitucional $\mathrm{n}^{\mathrm{o}}$ 65, estabelecendo: a criação do Estatuto da Juventude, destinado a regular os direitos dos jovens no país; e o Plano Nacional da Juventude, de duração decenal, projetando à articulação das várias esferas do poder público para a execução de políticas públicas para a juventude (Brasil, 2010).

O Ministério do Trabalho e Emprego, pela Lei No10.748 (Brasil, 2003), instituiu o Programa Primeiro Emprego. Tinha como objetivo central o combate ao desemprego juvenil por meio de ações que estimulassem a contratação de jovens no mercado formal de trabalho, sendo o público-alvo formado por jovens entre 16 e 24 anos, sem experiência de trabalho formal, provenientes de famílias com renda per capita inferior a meio salário mínimo ${ }^{1}$ e que apresentassem baixos níveis de escolaridade (Andrade e Rodrigues, 2008).

1 O salário mínimo no Brasil, em 2014, corresponde ao valor de $\mathrm{R} \$ 724,00$, o que equivale a cerca de $\$ 320$ dólares americanos. 
Em paralelo, o governo federal buscou parceiros para a realização de um retrato acerca da juventude brasileira. Por meio da participação de coletivos juvenis e organizações não governamentais, como aponta Sposito (2007), foi realizado o «Projeto Juventude», tendo como objetivo redigir um documento contendo um diagnóstico sobre os jovens brasileiros e uma proposta de diretrizes para a formulação de políticas públicas. Cabe colocar que o Projeto Juventude foi redigido pelo Instituto Cidadania que, atualmente, é denominado de Instituto Lula. O instituto foi responsável pela concepção dos projetos do governo de Luiz Inácio Lula da Silva, a saber: Projeto Moradia (2000), Projeto Fome Zero (2001), Projeto Energia Elétrica (2002), Projeto Segurança Pública (2002), Projeto Reforma Política (2003), Projeto Juventude (2004), Projeto Política de Apoio ao Desenvolvimento Local (2006) (Instituto Lula, 2013). O Projeto Juventude formalizou diversos levantamentos, dados, debates e pesquisas acerca das políticas para a juventude no país.

O governo federal realizou, também, um mapeamento dos programas federais já existentes voltados para o segmento da juventude. Foram identificadas 135 ações federais, que estavam vinculadas em 45 programas, sendo realizadas por 18 ministérios ou secretarias estaduais. Silva e Andrade (2009) apontam que, do total de ações, apenas 19 eram específicas para o público jovem na faixa etária de 15 a 24 anos e que as outras 112, ainda que incidissem sobre os jovens, não se voltavam exclusivamente a esse público.

Com isso, identificou-se a frágil institucionalidade, fragmentação e superposição das políticas federais de juventude, sugerindo a urgente necessidade de criar uma instância de coordenação e articulação, que tivesse, entre outras atribuições, de combater o paralelismo e a fragmentação das ações federais dirigidas ao público jovem (Silva e Andrade, 2009).

Como resultado desse processo, partindo da ideia de articulação entre os muitos projetos já existentes, ou seja, pelo princípio da intersetorialidade, o governo federal, através de uma de medida provisória apresentada no início de 2005, consolidada na Lei $\mathrm{N}^{\circ} 11.129$ de 30 de junho do mesmo ano, propôs a criação de dispositivos destinados aos jovens brasileiros de 15 a 29 anos, implementando: a Secretaria Nacional de Juventude (SNJ), o Conselho Nacional da Juventude (CONJUVE) e o Programa Nacional de Inclusão de Jovens (Projovem) (Brasil, 2005). 


\section{a) Secretária Nacional da Juventude (SNJ)}

A Secretaria Nacional da Juventude, vinculada à Secretaria Geral da Presidência da República, tem como função articular intersetorialmente as ações nacionais para a juventude (Brasil, 2013). Segundo os documentos oficiais, a agenda de governo para a juventude não se limita a um programa específico e, de forma transversal, está colocada nas ações de vários Ministérios (Brasil, 2011). Tal proposição se viabilizaria pela sua vinculação à Secretaria Geral da Presidência da República, que tem, por um lado, uma facilidade em realizar a conversa entre as ações interministeriais, e, por outro, ser um canal direto para efetivação das políticas. O desenho de uma Secretaria de Juventude não possuindo um «status» ministerial, tornou-se uma estratégia para a articulação entre os Ministérios visando à constituição de uma agenda pública da juventude.

A SNJ acompanha um movimento oriundo do formato de administração adotado pelos governos de Lula e da atual gestão da presidenta Dilma Roussef, que realizaram a criação de secretarias que assegurem a garantia de direitos a grupos populacionais e a execução de uma agenda pública federal específica. São exemplos em outras áreas: a Secretaria de Políticas de Promoção da Igualdade Racial (Brasil, 2003) e a Secretaria de Políticas para a Mulher (Brasil, 2010).

\section{b) Conselho Nacional da Juventude}

O Conselho Nacional da Juventude (CONJUVE), criado a partir do decreto presidencial No5.490 (Brasil, 2007), tem como finalidade formular e propor diretrizes da ação governamental, voltadas à promoção das políticas públicas para a população jovem (Brasil, 2009). Visa ao fomento de estudos e pesquisas sobre a realidade socioeconômica juvenil (Sposito, 2007) e ao estabelecimento do diálogo entre o Poder Executivo, o Poder Legislativo e a sociedade civil.

O CONJUVE tem como composição 60 membros, na proporção de $1 / 3$ de representantes do poder público e $2 / 3$ da sociedade civil, ou seja, 20 representantes do governo e 40 representantes da sociedade civil. Essa composição foi estruturada para que as ações fossem articuladas em todas as esferas governamentais (federal, estadual e municipal), com o intuito de que a política juvenil se transformasse, de fato, no Brasil, em uma política de Estado (Brasil, 2007). 
A parcela da sociedade civil, que é maioria no CONJUVE, reflete a diversidade dos atores sociais que contribuíram e contribuem para o enriquecimento desse diálogo. O Conselho conta com representantes dos movimentos juvenis, organizações não governamentais, especialistas e personalidades com reconhecimento público pelo trabalho nessa área. Os membros do Conselho são escolhidos para o mandato de dois anos, mediante eleição direta, e os cargos de presidente e vicepresidente são alternados, a cada ano, entre governo e sociedade civil (Brasil, 2007).

Cabe apontar que o CONJUVE foi criado a partir de uma iniciativa do governo federal e não da sociedade civil, o que revela a estratégia governamental para a criação de um aparato institucional para a juventude, mas não, necessariamente, a ascensão na esfera pública desse grupo populacional. No processo governamental, o mesmo decreto de lei estabeleceu a criação da SNJ concomitantemente com o CONJUVE e, ainda, a proposta do Programa Nacional de Inclusão de Jovens (Brasil, 2005). Essa articulação visava, segundo os documentos, consolidar a agenda pública de forma ampliada com diferentes componentes da estrutura política, ou seja, possuindo um órgão para execução da agenda, outro para sua representação e fiscalização, além de uma ação efetiva, como ponto de partida para sua implementação.

\section{c) Projovem}

A proposição da Política Nacional da Juventude (PNJ) em seu início tinha como ação prioritária a execução do Programa Nacional de Inclusão dos Jovens (Brasil, 2008). Trata-se de uma proposta com caráter emergencial, voltada para jovens de 18 a 24 anos, excluídos da escola e do mercado de trabalho. Castro e Aquino (2008) discursam sobre a composição do programa e de seu formato:

O Programa Nacional de Inclusão de Jovens foi lançado para atender os jovens de 15 até 29 anos que estão fora da escola e não possuem formação profissional, buscando unificar e integrar as diversas ações governamentais voltadas para este público, além de ampliar seu escopo e cobertura. Por comportar uma população bastante ampla e heterogênea, o novo programa está concebido em quatro eixos, que visam atender diferenciadamente a quatro grupos de jovens: i) ProJovem Urbano, que ficará a cargo da Secretaria Geral da Presidência da República; ii) ProJovem Campo, coordenado pelo Ministério da Educação; iii) ProJovem Trabalhador, cuja responsabilidade é do Ministério do Trabalho e Emprego; e iv) ProJovem 
Adolescente, que será gerido pelo Ministério do Desenvolvimento Social e Combate à Fome (Castro e Aquino, 2008:30).

O Projovem contempla em seus âmbitos específicos a aceleração de escolaridade, a qualificação profissional e a execução de ações comunitárias para os jovens, transferindo, em três das quatro modalidades do programa, o auxílio financeiro da ordem de $\mathrm{R} \$ 100,00$ reais (cerca de U\$40 dólares americanos) para os seus participantes. As ações do Projovem tem o recorte de classe social, sobretudo porque é destinado aos jovens de baixa renda. Segundo pesquisas realizadas diretamente nos coletivos de Projovens, a maior parte das orientações socioeducativas oferecidas não se dedica, de fato, ao conhecimento sobre melhores condições de transição para o mundo adulto (Sposito, 2007).

Pode-se dizer que houve a manutenção de ações «apenas» para o recorte de classe social, com uma proposição prioritária direcionada aos jovens pobres, ao invés de simbolizar uma mudança radical na concepção e financiamento. Consequentemente, não acarretou a efetiva execução de uma política para juventude, traduzindo-se, somente, numa readequação daquilo que já estava em execução por governos anteriores.

\section{Políticas UNIVERSAIS E POLÍtiCAS FOCAIS: O DEBATE EM TORNO DE ESTRATÉGIAS EQUÂNIMES DE ALCANCE AO PÚBLICO JOVEM}

O debate em torno da organização das políticas sociais e a sua forma de oferta, entre ações universais e focais, é permeada pela questão da priorização de um determinado grupo populacional, na proposição do enfoque de suas ações ou universalidade, otimizando os recursos estatais para a viabilidade do acesso ao direito de todos. Silva (2001), no debate acerca do acesso aos direitos sociais e da cidadania na América Latina, define:

La ciudadanía, es decir, el espacio de autonomía y libertad, política, civil y particularmente social y cultural, que los sujetos buscan o intentan abrir para sus vidas sociales se encuentra limitado, coartado, restringido por diversas circunstancias y factores. Entre éstas, no menor es la responsabilidad que le cabe a las instituciones del Estado (Silva, 2001:107).

Numa análise sobre o desenvolvimento das políticas sociais na América Latina, Draibe (1993) pontua que foram enquadradas «aos rigores 
dos ajustes macroeconômicos e à devastação social» (1993:92). Apresentam, então, a «deterioração dos serviços sociais públicos, a par do empobrecimento da população» (1993:101). Tal questão econômica estrutural passa a justificar a proposição de serem direcionadas às camadas mais pobres da população.

A focalização, decorre do fato de que os gastos sociais públicos chegam, em pequena proporção, aos setores pobres da sociedade e que, portanto, para eles, devem ser dirigidos, prioritariamente, os recursos para os programas sociais. Contudo, a pequena força política desses grupos populacionais, decorrentes de sua desorganização, e a pouca sensibilidade social dos neoliberais com relação a eles fazem com que a política de focalização termine por transformar-se numa neofilantropia (Mendes, 1993:51).

Por um lado, o enfoque das políticas sociais, por meio do discurso da necessidade de erradicação da pobreza e do atendimento aos mais necessitados, aplica-se a uma dimensão positiva, na medida em que, efetivamente, faz-se necessário o direcionamento de ações para aqueles que menos acessam aos bens sociais e à cidadania. Identifica-se, assim, ideários democráticos com equidade. Levando em consideração o quadro de desigualdade social vivenciado nos países da América Latina, tal dimensão ganha força para os argumentos ao seu favor.

Por outro lado, compõe estratégias globais que visam à manutenção da estabilidade política e à redução de conflitos que, em alguns momentos, camuflam proposições de corte de gastos, pautadas pela lógica econômica. Ainda, podem contribuir com relações preconceituosas e pejorativas destinadas aos «pobres», podendo ocasionar a «segmentação da cidadania que pode ocorrer através da duplicidade da política social: uma política para pobres (em geral uma pobre política) ao lado de uma política para ricos (em geral, rica, sofisticada e muitas vezes também financiada com recursos públicos)» (Draibe, 1993:100).

No campo das políticas para a juventude prevalece o mesmo debate: ela deve ter um recorte focal privilegiando os grupos juvenis populares no acesso aos seus direitos sociais? Certamente sim, porém, se ela se reduzir «apenas» a essas ações, perde sua potencialidade de se direcionar aos direitos dos jovens brasileiros e foca-se em ações geralmente «de pobre para pobre» com reprodução de valores morais, pouca efetividade e alcance social (Hein e Cárdenas, 2009). 


\section{AS AÇÕES E AS PUBLICAÇÕES OFICIAIS PARA A CONSOLIDAÇÃo DA AGENDA PÚBLICA PARA A JUVENTUDE}

Após a criação dos dispositivos governamentais, iniciou-se um processo de reorganização das ações políticas que já estavam vigentes no país para aquele segmento populacional e a adequação para a criação de novas propostas.

No interior da SNJ e do CONJUVE, em 2006 foi lançado um documento denominado «Política Nacional de Juventude: diretrizes e perspectivas» (Novaes, Cara e Moreira, 2006), sendo a primeira publicação do governo com essa denominação, fruto dos debates iniciais dos atores políticos para a implementação de uma agenda pública, de emendas que se tornariam ações efetivas da SNJ. O documento traz o debate realizado dentro das principais áreas elencadas como preocupação da política, sendo elas: Desenvolvimento integral (educação, trabalho, cultura e tecnologias da informação); qualidade de vida (meio ambiente, saúde, esporte e lazer); e vida segura (valorização da diversidade e respeito aos direitos humanos).

Além desse documento, foi lançado também um guia com os principais programas e projetos para a juventude no Brasil (Brasil, 2006). Os projetos estavam ligados a diferentes Ministérios (conforme apresentados na Tabela 1.) e, em sua maioria, já estavam em execução, não sendo criados pela SNJ. Tinham, então, o objetivo de serem articulados pela SNJ, conforme sua missão dentro do governo federal.

Em 2007, portanto após o lançamento do referido Guia (Brasil, 2006), o enfrentamento à violência e à criminalidade também entrou na agenda pública pela criação do Programa Nacional de Segurança Pública com Cidadania, ligado ao Ministério da Justiça. Com o objetivo de articular políticas de segurança com ações sociais tendo por públicoalvo os profissionais de segurança pública e os jovens de 15 a 24 anos à «beira da criminalidade», que se encontram ou já estiveram em conflito com a lei (Brasil, 2007). Analisando tais dados, observa-se que grande parte das ações realizadas se concentrava no Ministério da Educação, demonstrando uma concepção de ação política a partir de práticas educativas com a juventude, partindo do entendimento da educação como possível mecanismo de integração aos processos de exclusão social (Rivera, 2001). Outro destaque se dá nas ações advindas do Ministério dos Esportes, demonstrando uma percepção do esporte como medidas preventivas às problemáticas enfrentadas na vida dos jovens, projetando como um benefício ao jovem estar na escola e praticar esportes. 
TABELA 1: PROGRAMAS E AÇÕES DO GOVERNO FEDERAL PARA A JUVENTUDE

\begin{tabular}{|c|c|c|}
\hline MINISTÉRIO & Programas & DEFINIÇÃO \\
\hline \multirow{8}{*}{$\begin{array}{l}\text { Ministério da } \\
\text { Educação }\end{array}$} & $\begin{array}{l}\text { Programa Brasil } \\
\text { Alfabetizado }\end{array}$ & $\begin{array}{l}\text { Para jovens com mais de } 15 \text { anos que } \\
\text { não tiveram a oportunidade de estudar }\end{array}$ \\
\hline & $\begin{array}{l}\text { Programa Escola } \\
\text { Aberta }\end{array}$ & $\begin{array}{l}\text { Com a finalidade de abrir as escolas } \\
\text { públicas de Ensino Fundamental e } \\
\text { Médio nos finais de semana para } \\
\text { acesso a atividades educativas, cultu- } \\
\text { rais, de lazer e de geração de renda }\end{array}$ \\
\hline & $\begin{array}{l}\text { Programa de Inte- } \\
\text { gração da Educação } \\
\text { Profissional ao Ensi- } \\
\text { no Médio na Moda- } \\
\text { lidade de Educação } \\
\text { de Jovens e Adultos }\end{array}$ & $\begin{array}{l}\text { Oferta de vagas para jovens a partir } \\
\text { de } 21 \text { anos, em cursos profissionali- } \\
\text { zantes, que não tiveram acesso ao } \\
\text { Ensino Médio na idade regular }\end{array}$ \\
\hline & $\begin{array}{l}\text { Programa Universi- } \\
\text { dade para Todos, } \\
\text { ProUni }\end{array}$ & $\begin{array}{l}\text { Concede bolsas de estudo em insti- } \\
\text { tuições de ensino superior privadas }\end{array}$ \\
\hline & $\begin{array}{l}\text { Programa Saberes da } \\
\text { Terra }\end{array}$ & $\begin{array}{l}\text { Acesso e à permanência dos agricul- } \\
\text { tores familiares no sistema formal de } \\
\text { ensino }\end{array}$ \\
\hline & $\begin{array}{l}\text { Programa Escola de } \\
\text { Fábrica }\end{array}$ & $\begin{array}{l}\text { Com a finalidade a inclusão de jovens } \\
\text { de } 16 \text { a } 24 \text { anos no mercado de tra- } \\
\text { balho por meio de cursos de iniciação } \\
\text { profissional oferecidos nas empresas }\end{array}$ \\
\hline & $\begin{array}{l}\text { Programa de } \\
\text { Melhoria e Expansão } \\
\text { do Ensino Médio }\end{array}$ & $\begin{array}{l}\text { Expansão dos cursos profissionalizan- } \\
\text { tes e de vagas para o ensino médio } \\
\text { nas instituições federais }\end{array}$ \\
\hline & $\begin{array}{l}\text { Programa Nacional } \\
\text { do Livro Didático } \\
\text { para o Ensino Médio }\end{array}$ & $\begin{array}{l}\text { Distribuição de livros para os alunos } \\
\text { do ensino médio de escolas públicas }\end{array}$ \\
\hline \multirow{3}{*}{$\begin{array}{l}\text { Ministério dos } \\
\text { Esportes }\end{array}$} & $\begin{array}{l}\text { Programa } \\
\text { Bolsa Atleta }\end{array}$ & $\begin{array}{l}\text { Garantir apoio financeiro aos atletas } \\
\text { com mais de } 12 \text { anos que não contem } \\
\text { com patrocínio da iniciativa privada. }\end{array}$ \\
\hline & $\begin{array}{l}\text { Programa Segundo } \\
\text { Tempo }\end{array}$ & $\begin{array}{l}\text { Acesso à prática esportiva em período } \\
\text { contrário ao turno escolar }\end{array}$ \\
\hline & Praças da Juventude & $\begin{array}{l}\text { Construção de espaços esportivos nos } \\
\text { municípios. Em parceria com o Mi- } \\
\text { nistério da Justiça }\end{array}$ \\
\hline \multirow{2}{*}{$\begin{array}{c}\text { Ministério do } \\
\text { Desenvolvimento } \\
\text { Agrário }\end{array}$} & Pronaf Jovem & $\begin{array}{l}\text { Programa Nacional de Agricultura } \\
\text { Familiar voltado para filhos de agri- } \\
\text { cultores, com idade entre } 16 \text { e } 25 \text { anos }\end{array}$ \\
\hline & $\begin{array}{l}\text { Programa Nossa } \\
\text { Primeira Terra }\end{array}$ & $\begin{array}{l}\text { Linha de financiamento voltada a } \\
\text { jovens rurais para aquisição de imó- } \\
\text { veis e investimento em infra-estrutura }\end{array}$ \\
\hline
\end{tabular}


CONTINUACIÓN

\begin{tabular}{|c|c|c|}
\hline \multirow{2}{*}{$\begin{array}{l}\text { Ministério da } \\
\text { Defesa }\end{array}$} & Projeto Rondon & $\begin{array}{l}\text { Objetivo de levar estudantes univer- } \\
\text { sitários para estágios em regiões } \\
\text { menos favorecidas do país }\end{array}$ \\
\hline & $\begin{array}{l}\text { Programa Soldado } \\
\text { Cidadão }\end{array}$ & $\begin{array}{l}\text { Preparar o jovem egresso do serviço } \\
\text { militar para o mercado de trabalho }\end{array}$ \\
\hline $\begin{array}{l}\text { Ministério do } \\
\text { Desenvolvimento } \\
\text { Social e Combate } \\
\text { à Fome }\end{array}$ & $\begin{array}{l}\text { Projeto Agente } \\
\text { Jovem }\end{array}$ & $\begin{array}{l}\text { Oferta aos jovens de } 15 \text { a } 17 \text { anos, no } \\
\text { horário contrário ao turno escolar, } \\
\text { capacitação teórico-prática para a } \\
\text { permanência do jovem no ensino e } \\
\text { futura inserção no mercado de tra- } \\
\text { balho }\end{array}$ \\
\hline $\begin{array}{l}\text { Ministério do } \\
\text { Meio Ambiente }\end{array}$ & $\begin{array}{l}\text { Programa Juventude } \\
\text { e Meio Ambiente }\end{array}$ & $\begin{array}{l}\text { Incentivo ao debate sobre o tema } \\
\text { entre os jovens de } 15 \text { a } 29 \text { anos para a } \\
\text { formação de lideranças ambientalistas }\end{array}$ \\
\hline $\begin{array}{l}\text { Ministério do } \\
\text { Trabalho } \\
\text { e Emprego } \\
\end{array}$ & $\begin{array}{l}\text { Programa Nacional } \\
\text { de Estímulo ao } \\
\text { Primeiro Emprego } \\
\end{array}$ & $\begin{array}{l}\text { Para jovens desempregados de } 16 \text { a } \\
24 \text { anos com a oferta de qualificação } \\
\text { socioprofissional }\end{array}$ \\
\hline $\begin{array}{l}\text { Ministério da } \\
\text { Cultura }\end{array}$ & $\begin{array}{l}\text { Programa Cultura } \\
\text { Viva }\end{array}$ & $\begin{array}{l}\text { Propósito potencializar iniciativas } \\
\text { culturais já existentes como meio de } \\
\text { acesso para todos os cidadãos }\end{array}$ \\
\hline
\end{tabular}

Fonte: Brasil, 2006.

Os projetos e programas que estavam em execução naquele período marcaram uma não linearidade em suas proposições, uma vez que surgiram de ações isoladas de diversos Ministérios. Não constituíam um traçado metodológico unificado, caracterizando-se mais como um conjunto de projetos, com diferenças ideológicas, do que como uma política pública (Sposito e Carrano, 2003).

Pode-se dizer que uma das ações que poderia ter sido priorizada pela Secretaria Nacional de Juventude seria o alinhamento e o redenho das ações já em curso naquele momento, conforme oficializado em suas proposições. Entretanto, não se verificou mudanças nos desenhos dos projetos a partir das ações da SNJ, não efetivando uma prática de intersetorialidade entre as múltiplas ações que estavam em desenvolvimento.

Em 2007, quando a Política Nacional de Juventude completava dois anos, o governo federal iniciou nova discussão para redesenhar tal política, que ainda estava presa a alguns vícios de criação (Silva e Andrade, 2009), ou seja, ao paradigma do jovem como «problema» (Abramo e León, 2005).

Assim os quatro principais desafios que se colocavam para a Política Nacional de Juventude em 2007 eram: i) ampliar o potencial de integração 
entre os programas emergenciais e destes com outro conjunto de ações consideradas mais estruturantes, vinculadas às áreas de educação, saúde, esporte e cultura; ii) aumentar a escala de atendimento dos programas emergenciais para todo o universo de jovens brasileiros considerados excluídos, considerando juventude a faixa etária compreendida entre 15 a 29 anos; iii) otimizar recursos; e iv) aumentar a eficácia (Silva e Andrade, 2009:52).

Em conjunto à readequação da política iniciou-se o processo de criação da $1^{a}$ Conferência Nacional de Políticas Públicas de Juventude, realizada entre 27 e 30 de abril de 2008, em Brasília, Distrito Federal, Brasil. Organizada pelo CONJUVE e pela SNJ a conferência teve por objetivo criar um espaço de diálogo entre o governo e a sociedade civil para ofertar subsídios na consolidação da política da juventude e a inclusão permanente do tema na agenda das políticas públicas do Estado Brasileiro. Segundo Castro e Abramovay (2009), a Conferência mobilizou 400 mil pessoas em municípios e estados brasileiros, sendo recebidos 260 relatórios referentes a 841 Conferências Municipais e Regionais e 689 Conferências Livres, 26 relatórios de Conferências Estaduais (uma por estado), totalizando 4.492 propostas sintetizadas em 548 propostas-sínteses, distribuídas em 16 temas. A conferência contou com a participação de cerca de 3.000 pessoas entre delegados, imprensa, pesquisadores e convidados.

Três anos após a primeira conferência, em 2011, já no primeiro ano de governo da presidenta Dilma Rousseff, foi realizada a $2^{\mathrm{a}}$ Conferência Nacional de Juventude, que trouxe como temática «Conquistar direitos e desenvolver o Brasil!». Dessa conferência não foram ainda disponibilizados dados quanto aos números de delegados, municípios e propostas. Foram, apenas, apresentadas as suas resoluções finais e moções. Elas permeiam temáticas que estão em debate atualmente no país, como a destinação de $10 \%$ do Produto Interno Bruto (PIB) para a EDUCAÇÃO, o «passe livre» no transporte público para os estudantes, as políticas de cotas para afrodescendentes em diversos espaços públicos, entre outras resoluções. Ou seja, temas da ordem do dia em consonância com as necessidades dos jovens.

Porém, além de temáticas relacionadas à vida social juvenil, também estão sinalizadas, em suas resoluções, temáticas cujo debate é de responsabilidade de toda sociedade civil, sobre a justificativa da juventude não estar alheia aos outros movimentos (Brasil, 2013). Como exemplo disso: uma resolução do eixo saúde da conferência trata da redução da jornada de trabalho para os servidores da saúde; outro 
exemplo está no eixo de cultura, que aponta em uma resolução a questão de cotas para a produção nacional nos veículos da mídia (cinema, rádio, televisão) (Brasil, 2013).

O uso do espaço da Conferência Nacional da Juventude por atores que promovem a interface das temáticas e que, por sua vez, também militam em outros espaços de temáticas específicas (como a Conferência Nacional da Saúde, Conferência Nacional da Cultura, por exemplo), é tido politicamente como uma ação estratégica para fortalecer e conseguir uma ampla divulgação de seus projetos, mas que não dizem diretamente sobre o público juvenil.

É necessário refletir sobre a construção de espaços públicos, dentro das premissas propostas pelos órgãos federais administrativos para a juventude (SNJ e CONJUVE), nos quais as conferências possam trazer, em suas resoluções, debates reais acerca daquilo que efetivamente poderá incidir na vida do jovem. As interfaces são importantes, porém, poderiam ser realizadas em outros contextos e não em espaços tão específicos como o da Conferência Nacional da Juventude, pois podem atuar na contramão do que desejam, ou seja, na invisibilidade das demandas juvenis específicas. Esse fórum deveria legitimar a discussão acerca da juventude e seus direitos, debatendo o que, efetivamente, será responsabilidade coletiva na sociedade brasileira sobre a população juvenil.

Os gestores da política apontam que a consolidação das Conferências é resultado principalmente da institucionalização dos órgãos nacionais voltados para a juventude que realizam a efetivação dos assuntos determinantes da juventude na agenda pública. Ainda não há, por questões de temporalidade em que as conferências foram realizadas, como apontar se o que foi decidido como necessidades e colocado no documento final daqueles encontros, no discurso dos gestores, tornam-se metas e ações efetivas para o governo federal.

$\mathrm{O}$ que se pode apontar no momento é uma continuidade do trabalho iniciado no governo Lula, em suas duas gestões, e na gestão da presidenta Dilma Rousseff. Nos últimos anos, além da realização da $2^{\mathrm{a}}$ conferência, houve a continuidade dos programas já implantados, como a restruturação do Projovem e a criação de novos programas com execução da SNJ, conforme detalhado na Tabela 2. 
TABELA 2: PROGRAMAS E AÇÕES CRIADOS PELA SNJ A PARTIR DE 2012

\begin{tabular}{|l|l|}
\hline PROGRAMAS & OBJETIVOS \\
\hline Plano «Juventude Viva» & $\begin{array}{l}\text { Incorpora a dimensão preventiva da } \\
\text { violência sofrida pela população negra, } \\
\text { articulando políticas sociais em diver- } \\
\text { sos campos no combate às desigualda- } \\
\text { des raciais e na garantia dos direitos } \\
\text { humanos }\end{array}$ \\
\hline Programa «Estação Juventude» & $\begin{array}{l}\text { Ampliar o acesso ao jovem, ofertando } \\
\text { tecnologias sociais para o desenvolvi- } \\
\text { mento de locais permanentes para a } \\
\text { juventude }\end{array}$ \\
\hline $\begin{array}{l}\text { Participatório, } \\
\text { Observatório Participativo da Juventude }\end{array}$ & $\begin{array}{l}\text { Espaço virtual, inspirado nas redes } \\
\text { sociais, voltado à produção do con- } \\
\text { hecimento sobre/para a juventude } \\
\text { brasileira, com participação e mobili- } \\
\text { zação social }\end{array}$ \\
\hline $\begin{array}{l}\text { Programa de Inclusão Produtiva, For- } \\
\text { mação Cidadã e Capacitação para a } \\
\text { Geração de Renda da Juventude Rural }\end{array}$ & $\begin{array}{l}\text { Promover ações que estimulem a } \\
\text { produção agroecológica e as práticas } \\
\text { de geração de renda agrícola e não } \\
\text { agrícolas sustentáveis }\end{array}$ \\
\hline
\end{tabular}

Fonte: Brasil, 2013.

A Tabela 2 é o retrato de ações mais independentes da SNJ, na qualidade de uma instituição do governo federal que planeja e executa ações políticas para o seu público-alvo: a juventude. Tais ações não possuem uma projeção para a juventude brasileira em sua totalidade, mas para grupos que demandam projetos característicos.

Além da implantação desses programas nos últimos anos, a mais recente aposta da gestão como proposição política foi o Estatuto da Juventude, sancionado pela Presidência da República em 05 de julho de 2013. O Estatuto tem por objetivo instituir os direitos dos jovens trazendo os princípios e as diretrizes das políticas nacionais da juventude e o Sistema Nacional de Juventude (Brasil, 2013), com a finalidade de articular uma rede de informações entre municípios, estados e a união para consolidação de conselhos e das políticas públicas.

Por ser um documento muito recente, as primeiras impressões que se têm são de uma aposta na implementação da Política para a Juventude a partir do seu princípio de direito, como um norteador para obter novas propostas.

O Estatuto da Juventude é um instrumento que assegura os direitos dos jovens do país, porém, mesmo sendo universal, apresenta em 
seus artigos um recorte de classe social que prioriza a juventude pobre e toma algumas medidas de caráter assistencialista, exemplificado na seção que trata da mobilidade urbana:

Secção IX: Do direito ao território e a mobilidade.

Art. 32. No sistema de transporte coletivo interestadual, observar-se-á, nos termos da legislação específica:

I - a reserva de 2 (duas) vagas gratuitas por veículo para jovens de baixa renda;

II - a reserva de 2 (duas) vagas por veículo com desconto de 50\% (cinquenta por cento), no mínimo, no valor das passagens, para os jovens de baixa renda, a serem utilizadas após esgotadas as vagas previstas no inciso I (Brasil, 2013).

$\mathrm{O}$ artigo acima descrito certamente trata de tema atual e de relevância para a realidade dos centros urbanos, principalmente das grandes cidades, abrangendo, pela proposição do foco das ações, o acesso à mobilidade e à viabilidade do direito de ir e vir. Contudo, tal proposição poderia ter caráter universal e traçar regulamentações que beneficiassem a juventude nacional, independente de sua classe social.

$\mathrm{O}$ desenho legislativo em vigor se dá pelas diferenças e ênfases institucionais dos programas e pela constituição que as políticas tendem a se delinear. Tal questão fica mais clara à medida que os mecanismos institucionais no interior do Legislativo e do Poder Executivo entrem em ação (Sposito, 2007), imprimindo sua lógica de governabilidade.

\section{CONSIDERAÇÕES FINAIS}

Pelo panorama apresentado, do resgate histórico até a atualidade, passando por outros estudos que também buscaram entender a evolução das políticas públicas para a juventude no Brasil (Sposito e Carrano, 2003), podemos afirmar que houve um avanço na última década, principalmente no desenho institucional dentro da agenda pública do governo brasileiro. O que não é «pouco», pois a entrada na agenda é o primeiro passo para que ações possam ser debatidas, disputadas e, efetivamente, implementadas no contexto das políticas sociais.

Porém, a institucionalização da agenda em governos, dentro do contexto da América Latina, demonstra que a criação de órgãos executivos, de participação ou legislações não foi suficiente, até o momento, para garantir com efetividade aspectos democráticos nas ações das políticas públicas para a juventude (Brenner, Lânes e Carrano, 2005). 
O levantamento do discurso público sobre a temática da juventude dentro do retrato histórico demonstra uma recente institucionalidade desse grupo populacional na esfera pública e sua construção tem se dado de modo lento e imbricada por diferentes concepções e visões de mundo. Entretanto, é importante que a construção institucional das políticas seja um processo com participação dos diversos atores da sociedade, seguindo com cautela as propostas de atalho para a invenção de novos organismos públicos (Brenner, Lânes e Carrano, 2005), buscando garantir uma construção que inclua uma ampla participação de todos os responsáveis e envolvidos com o movimento de juventude no país.

A defesa de desenhos institucionais específicos para a gestão das políticas de juventude reuniu atores importantes nos últimos anos e exprime consensos que orientaram os debates e algumas ações no nível federal (Sposito, 2007), mas é preciso atentar-se para o recorte de classe social colocado e mantido.

Espera-se que as proposições atuais sejam estratégias temporárias que venham a ser institucionalizadas ao longo dos próximos anos nas futuras gestões governamentais. Almeja-se que, num futuro próximo, possa se afirmar a incorporação efetiva da demanda dos jovens na agenda pública brasileira. Ainda, espera-se que o princípio da universalidade venha a ocupar a preocupação dos gestores, num processo progressivo que caminhe para a efetividade de uma real política para a juventude (Mannhheim, 1972) e não apenas de projetos sociais isolados e desarticulados destinados aos jovens pobres (Sposito, 2007). Em outras palavras, espera-se, em consonância com o pensamento de Mannheim, que a política para a juventude possa, efetivamente, contribuir com o processo democrático.

Reduzindo a uma só frase, o problema consiste em que, nesse nosso mundo moderno, tudo é político, o Estado está em toda a parte e a responsabilidade política acha-se entrelaçada em toda a estrutura da sociedade. A liberdade consiste não em negar essa interpretação, mas em definir seus usos legítimos em todas as esferas, demarcando limites e decidindo qual deve ser o caminho da penetração, e, em última análise, em salvaguardar a responsabilidade pública e a participação de todos no controle das decisões (Mannheim, 1972:66).

Portanto, no processo histórico de constituição e implementação da política social brasileira, fica evidente que as ações que estão em vigência para a juventude atualmente necessitarão, nas próximas gestões, serem revistas, ou efetivando o discurso de que são políticas para uma 
juventude pobre, ou seja, numa escolha de focalização de um determinado segmento; ou ampliando as projeções para outros grupos juvenis, criando novas demandas e ações para as problemáticas da juventude de uma forma universal.

As políticas estabelecidas atualmente retratam um formato de governo e suas prioridades. Ainda é recente a projeção do legado que vem sendo construído para que se possam estabelecer conclusões. Entretanto, os projetos em curso vão numa direção diferente à consolidação de uma política que possibilite o acesso aos direitos sociais e à cidadania, o que ainda não está institucionalizado na agenda política brasileira. Segundo Lobato (2009), o que se verifica «são híbridos de políticas progressistas com restrições importantes na cobertura, no financiamento e na qualidade da atenção, ainda com baixo impacto na construção da cidadania social prevista» (2009:723).

Projetar uma perspectiva longitudinal dentro do que vem sendo consolidado implica em expandir as políticas nos aspectos intersetoriais do governo, provocando a implementação efetiva das ações projetadas nos diferentes níveis políticos, atentando-se para uma real garantia de direitos da população juvenil. Ainda não há como avaliar os benefícios, por exemplo, que o Estatuto da Juventude pode trazer para a população do país, porém é preciso que se debata a assunção da demanda na esfera pública social.

O desafio que está posto é o de expandir o olhar sobre o jovem em todas as áreas buscando novas perspectivas, através de novas formas de participação que lhe são próprias, atuando no centro de sua própria construção, como indivíduos, coletivos e sujeitos sociais (Mannheim, 1972; Rivera, 2001) com direitos garantidos os quais devem ser assumidos pela sociedade civil e política do país.

Porém, para que isso se efetive, faz-se necessária a assunção desse público como demanda social, ou seja, o reconhecimento coletivo de suas necessidades e o consenso sobre o investimento público para eles. Entretanto, a questão das políticas sociais tem entrado em conflito com a visão moral e social acerca da juventude, demonstrando uma certa dúvida sobre a necessidade de ampliação de investimentos para toda a juventude brasileira. Observam-se discursos que abarcam posições tradicionais e extremistas que ora situam os jovens como a «redenção da humanidade», ora como a ameaça ou desvio à ordem social posta (Barbiani, 2007).

Todavia, as «políticas públicas são, assim, parte importante da institucionalização de valores e regras da vida coletiva. Elas orientam 
concepções, definem estratégias, alocam recursos e distribuem valores para a sociedade que podem contribuir para consolidar uma nova institucionalidade em relação a temas distintos» (Lobato, 2009:722), como as demandas juvenis.

As Políticas Públicas para a Juventude no Brasil, como aponta Castro e Aquino (2008), devem continuar na ampliação da proposta da Política Nacional de Juventude para todos os segmentos que compõem a juventude, integrando programas emergenciais com os programas universais, sob a ótica de direitos sociais, no princípio de que se trata de sujeito de direitos, sempre considerando as suas especificidades e a integralidade de suas demandas.

Há que associar as políticas focalizadas com as políticas universais e integrá-las em sistemas universais de seguridade e proteção social. Políticas progressistas sem efetividade comprometem a coesão social democrática. [Tem-se] o ideal da democracia com justiça social. É possível e necessário reconstruir esse ideal (Lobato, 2009:728).

Essa (re)construção implica em mudanças de paradigmas acerca das concepções de juventude para que possamos atrelar a resolução das políticas públicas com as reais necessidades que abarcam a trajetória da juventude como um todo e, também, para seus subgrupos específicos.

Espera-se que o Brasil e toda a América Latina possam caminhar por trajetórias que não priorizem apenas a ordem econômica mundial, mas sim tracem planos criativos e equitativos que busquem viabilizar $\mathrm{o}$ acesso aos direitos sociais e à cidadania de todos, incluindo sua juventude.

SÃO PAULO (BRASIL), FEBRERO 2014

RECIBIDO: FEBRERO 2014

ACEPTADO: MAYO 2014 


\section{REFERENCIAS BIBLIOGRÁFICAS}

ABRAMO, HelENA W. E LEÓN, OSCAR DÁVILA (2005): Juventude e adolescência no Brasil. Referências conceituais. São Paulo: Ação Educativa. (2005): «Condição juvenil no Brasil contemporâneo». In: H. ABRAMO y P. BRANCO: Retratos da juventude brasileira: análise de uma pesquisa nacional. São Paulo: Instituto Cidadania e Fundação Perseu Abramo.

AREndt, Hannah (2007): A condição humana. Rio de Janeiro: Forense Universitária.

BARBIANI, RosÂNGELA (2007): «Mapeando o discurso teórico latinoamericano sobre juventude(s): a unidade na diversidade». Textos \& Contextos $\mathrm{N}^{\circ} 01$. Porto Alegre.

BRASIL (1988): Constituição da República Federativa do Brasil. Brasília: Presidência da República.

(1990): Lei No8069 de 13 de julho de 1990 que institui o Estatuto da Criança e do Adolescente. Brasília: Presidência da República.

(2003): Decreto $\mathrm{N}^{\mathrm{o}} 10.678$ de 23 de maio de 2003. Cria a Secretaria Especial de Políticas de Promoção da Igualdade Racial. Brasília: Presidência da República.

_ (2003): Decreto No10.683 de 28 de maio de 2003. Dispõe da organização da Presidência da República e dos Ministérios, e dá outras providências. Brasília: Presidência da República.

(2003): Decreto $N^{\circ} 10.748$ de 22 de outubro de 2003. Revogado pela Lei $\mathrm{N}^{\mathrm{o}} 11.692$, de 2008. Cria o Programa Nacional de Estímulo ao Primeiro Emprego para Jovens, acrescenta dispositivo á Lei $\mathrm{N}^{\circ} 9.608$, de 18 de fevereiro de 1998, e dá outras providências. Brasília: Presidência da República.

(2005): Decreto No11.129 de 30 de junho de 2005. Institui o Programa Nacional de Inclusão de Jovens - ProJovem; cria o Conselho Nacional da Juventude - CNJ e a Secretaria Nacional de Juventude; altera as Leis $\mathrm{N}^{\mathrm{o}} 10.683$, de 28 de maio de 2003, e 10.429, de 24 de abril de 2002; e dá outras providências. Brasília: Presidência da República.

(2005): Decreto №5.490 de 14 de julho de 2005. Dispõe sobre a composição e funcionamento do Conselho Nacional de Juventude e dá outras providências. Brasília: Presidência da República.

(2006): Guia de Políticas Públicas de Juventude. Brasília: Secretária Nacional da Juventude.

(2007): Decreto $N^{\circ} 11.530$ de 24 de outubro de 2007. Institui o Programa Nacional de Segurança Pública com Cidadania - PRONASCI e dá outras providências. Brasília: Presidência da República.

(2009): Natureza, Composição e Funcionamento, agosto de 2005/março de 2007. Brasília: Conselho Nacional da Juventude.

(2010): Decreto No12.314 de 19 de Agosto de 2010. Cria a Secretaria de Políticas para as mulheres; altera as Leis $\mathrm{N}^{\mathrm{os}} 10.683$, de 28 de maio 
de 2003, que dispõe sobre a organização da Presidência da República e dos Ministérios, 8.745, de 9 de dezembro de 1993, que dispõe sobre a contratação por tempo determinado para atender a necessidade temporária de excepcional interesse público, e 8.029, de 12 de abril de 1990, que dispõe sobre a extinção e dissolução de entidades da administração pública federal; revoga dispositivos da Lei $\mathrm{N}^{\circ} 10.678$, de 23 de maio de 2003; e dá outras providências. Brasília: Presidência da República.

(2010): Emenda Constitucional $\mathrm{N}^{\circ} 65$ de 13 de julho de 2010. Altera a denominação do Capítulo VII do Título VIII da Constituição Federal e modifica o artigo 227, para cuidar dos interesses da juventude. Brasília: Presidência da República.

- (2011): Propostas Finais Aprovadas. Brasília: $2^{\mathrm{a}}$ Conferência Nacional da Juventude.

(2011): Resoluções Finais para Desenvolver o Brasil. Brasília: $2^{\mathrm{a}}$ Conferência Nacional da Juventude.

(2011): Reflexões sobre a Política Nacional da Juventude, 2003-2010. Brasília: Secretária Nacional da Juventude.

(2013): Cartilha Políticas Públicas de Juventude. Brasília: Secretária Nacional da Juventude.

- (2013): Decreto $\mathrm{N}^{\circ} 12.852$ de 5 de agosto de 2013. Institui do Estatuto da Juventude e dispõe os direitos dos jovens, os princípios e as diretrizes das políticas públicas de juventude e o Sistema Nacional de Juventude. Brasília: Presidência da República.

BRenNer, ANA Karina; PATrícia LÂNes, PAUlo CÉsar Rodrigues CARRANO (2005): «A Arena das políticas públicas de juventude no Brasil: Processos sociais e propostas políticas». Jovenes $\mathrm{N}^{\circ} 22$. México: IMJ.

CAStro, Jorge Abrahão; Aquino, LuSEni MARIa Cordeiro (2008): $J u-$ ventude e políticas sociais no Brasil. Brasília: IPEA.

CASTRO, MARY GARCIA y MYRIAM ABRAMOVAY (2009): «Quebrando mitos: juventude, participação e políticas. Perfil, percepções e recomendações dos participantes da $1^{\text {a }}$ Conferência Nacional de Políticas Públicas para a Juventude». Brasília: RITLA.

Dagnino, Evelina (2002): Sociedade civil e espaços públicos no Brasil. São Paulo: Paz e Terra.

DRAIBE, SONIA (1993): «As políticas sociais e o neoliberalismo». Revista da USP $\mathrm{N}^{\circ} 13$

GASPARI, ElIO (2002): A ditadura escancarada (as ilusões armadas). São Paulo: Companhia das Letras.

HEIN, KERSTIN y ANA CÁRDENAS (2009): «Perspectivas de juventude en el imaginário de la política pública». Última Década $\mathrm{N}^{\circ} 30$. Valparaíso: Ediciones CIDPA.

INSTITUTO LULA (2013): «Projetos realizados».

Disponível em: www.institutolula.org. 
LobAto, LeNAURA DE VASCONCELOS Costa (2009): «Dilemas da institucionalização de políticas sociais em vinte anos da Constituição de 1988». Ciência e Saúde Coletiva №14, Rio de Janeiro.

Malfitano, ANa PaUla SerRata (2011): «Juventude e contemporaneidade: entre a autonomia e a tutela». Etnográfica $\mathrm{N}^{\circ} 15$. Lisboa: CRIA.

MANNHEIM, KARL (1972): Liberdade, poder e planificação democrática. Tradução: Miguel Maillet. São Paulo: Mestre Jou.

MENDES, EUGÊNIO VILAÇA (1993): «As políticas de saúde no Brasil nos anos 80: a conformação da reforma sanitária e a construção da hegemonia do projeto neoliberal». In: EUGÊNIO VILAÇA MENDES (org.): Distrito sanitário: o processo social de mudança das práticas sanitárias do sistema único de saúde. São Paulo/Rio de Janeiro: Hucitec/Abrasco.

Novaes, Regina; Daniel Cara y Danilo Moreira (2006): Política nacional da juventude: diretrizes e perspectivas. Brasília: Conselho Nacional da Juventude.

Novaes, ReginA (2012): «As juventudes e a luta por direitos». Le monde diplomatique Brasil N64. São Paulo: Instituto Pólis.

SILVA, CARLa REgINA y Roseli ESQUeRdo LOPES (2009): «Adolescência e juventude: entre conceitos e políticas pública». Cadernos de Terapia Ocupacional da UFSCar $\mathrm{N}^{\circ}$ 2. São Carlos.

SILVA, ENID ROCHA ANDRADE y CARLA COELHO ANDRADE (2009): «A política nacional de juventude: avanços e dificuldades». In: CASTRO et al.: Juventude e políticas sociais no Brasil. Brasília: IPEA.

Silva, JuAn Claudio (2001): «Ciudadanía: entre el debate crítico, la lucha política y la utopía». Última Década $\mathrm{N}^{\circ} 14$. Valparaíso: Ediciones CIDPA.

Sposito, MARILIA PONTES y PAUlo CÉSAR CARRANo (2003): «Juventude e políticas públicas no Brasil». Revista Brasileira de Educação $\mathrm{N}^{\circ} 24$.

— (2007): Espaços públicos e tempos juvenis: um estudo de ações do poder público em cidades de regiões metropolitanas brasileiras. São Paulo: Ação Educativa.

RIVERA, DANIEL CONTRERAS (2001): «Política social de juventud: ¿excluir o integrar a que?». Última Década $\mathrm{N}^{\circ} 14$. Valparaíso: Ediciones CIDPA. 